\title{
The Effects of Different Nickel-Ruthenium on SiO2 Catalyst Synthesis Methods toward Catalytic Activity of Methane Dry Reforming
}

\author{
Anatta Wahyu Budiman*, Nisriina ‘Abidah Qurrotul’aini, Nurul Latifah, Puan Hemas Dewani, Shafira \\ Rachmadhani, Sofiana Mukti Wigati \\ ${ }^{*}$ Chemical Engineering Department, Engineering Faculty, Universitas Sebelas Maret, Surakarta, Indonesia 57126 \\ ${ }^{*}$ Corresponding author: budiman @staff.uns.ac.id \\ DOI: https://dx.doi.org/10.20961/equilibrium.v5i2.55175
}

Article History

Received: 17-09-2021, Accepted: 13-01-2022, Published: 18-01-2022

Keywords:

catalyst, dry reforming, greenhouse gases, syngas

\begin{abstract}
The presence of greenhouse gases in the atmosphere has triggered global warming and climate change. An effective approach to overcome these issues is to convert greenhouse gases into syngas. In this study, $\mathrm{Ni}-\mathrm{Ru} / \mathrm{SiO}_{2}$ catalyst was used to catalyze the dry reforming process of methane $\left(\mathrm{CH}_{4}\right)$ and carbon dioxide $\left(\mathrm{CO}_{2}\right)$ into syngas. The catalyst was prepared using different synthesis protocols: sol gel-coprecipitation and impregnation methods. Characterization using Brunauer Emmett Teller analysis showed that the catalyst prepared using both methods exhibited comparable pore diameters and high surface areas. The $\mathrm{X}$-ray diffractometer analysis also indicated the presence of different $\mathrm{NiO}, \mathrm{RuO}_{2}$, and $\mathrm{SiO}_{2}$ phases. Furthermore, the activity of the catalyst was investigated using a fixed bed reactor. Based on the results, the optimum catalytic activity was obtained from the catalyst prepared via the sol gel-coprecipitation method, with an average $\mathrm{CH}_{4}$ and $\mathrm{CO}_{2}$ conversions of $37 \%$ and $50 \%$, respectively. In addition, our catalyst also showed a $114 \%$ higher $\mathrm{CH}_{4}$ conversion with an enhanced $\mathrm{H}_{2} / \mathrm{CO}$ ratio compared to identical catalysts from other studies.
\end{abstract}

\section{INTRODUCTION}

According to the US Environmental Agency in 2018, the main components of greenhouse gases are carbon dioxide $\left(\mathrm{CO}_{2}\right)$ and methane $\left(\mathrm{CH}_{4}\right)$, with a percentage of $80 \%$ and $10 \%$, respectively (Figure 1). The presence of greenhouse gases in the atmosphere can induce the rise of global surface temperature of up to $1.1^{\circ} \mathrm{C}$ [1]. This issue can trigger global climate change and reduce the stability of the climate system, as well as its tendency to cause global warming.

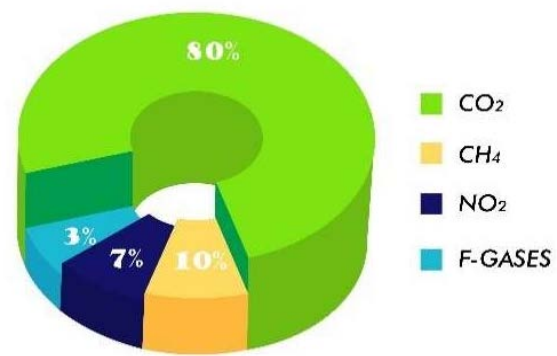

Figure 1. Percentage of Greenhouse Gas Components in the Atmosphere [2]

The National Oceanic and Atmospheric Administration Earth System Research Laboratory (2020) reported an increase in atmospheric $\mathrm{CO}_{2}$ concentration, with an average of 1.84 ppm per year in the past 41 years (1979-2020). A similar phenomenon was also observed for $\mathrm{CH}_{4}$ concentration in the atmosphere. In 2007-2013, an increase in $\mathrm{CH}_{4}$ concentration with an average of $5.7 \pm 1.1 \mathrm{ppb}$ per year was reported. From 2014 to 2019, the rise of global $\mathrm{CH}_{4}$ sharply increased to an average of $9.3 \pm 2.2 \mathrm{ppb}$ per year. In 2019, the $\mathrm{CH}_{4}$ concentration reached 10.4 $\pm 0,6$ ppb.

An effective approach to overcome these problems is to utilize the greenhouse gases via the decomposition of $\mathrm{CH}_{4}$, involving $\mathrm{CO}_{2}$ to produce synthetic gas (syngas). The syngas can be converted into alternative fuels, i.e., dimethyl ether (DME), methanol, and hydrogen [3]. The decomposition of $\mathrm{CH}_{4}$ utilizing $\mathrm{CO}_{2}$ is also called dry 
reforming (DMR). The DMR is a simple and environmentally friendly technique.

In order to optimize the dry reforming process of $\mathrm{CH}_{4}$, an efficient catalyst is required. In this study, $\mathrm{Ni}-\mathrm{Ru} / \mathrm{SiO}_{2}$ catalyst was employed as the catalyst for the dry reforming of $\mathrm{CH}_{4}$. The use of nickel catalyst is due to its high catalytic activity. However, this metal is still vulnerable to coke poisoning and tends to deactivate quickly [4]. For these reasons, the addition of precious metals such as Ru to enhance the stability of the nickel catalyst in stimulating $\mathrm{CO}_{2}$ activation and coke gasification is needed. Those statement is supported by previous research which $\mathrm{CH}_{4}$ conversion at reforming reaction is increase to $64 \%$ from $30 \%$ by using $\mathrm{Ru}$ as a precious metals [5]. Another component that is crucial in catalyst design is catalyst support. $\mathrm{SiO}_{2}$ is a promising candidate that can act as catalyst support owing to its mesoporous structure that is more favourable for the dry reforming of methane. Moreover, $\mathrm{SiO}_{2}$ is selected because of its high thermal stability, well-ordered porous channels, and high surface area that can improve the dispersion and accessibility of the nickel catalyst active sites.

\section{MATERIALS AND METHODS}

\subsection{Tools and Materials}

The tools used in this project included an Erlenmeyer flask, a hot plate, a magnetic stirrer, a dropping pipette, an oven, a mortar with a pestle, a furnace, an 80-mesh sieve, a beaker glass, a glass stirrer, a measuring cylinder, a stand, clamps, a thermometer, a $\mathrm{pH}$ indicator, a glass funnel, a crucible dish, and a fixed bed reactor. The materials used in this study comprised $\mathrm{NiSO}_{4} \cdot 6 \mathrm{H}_{2} \mathrm{O}, \mathrm{Ru}(\mathrm{NO})\left(\mathrm{NO}_{3}\right)_{\mathrm{x}}(\mathrm{OH})_{\mathrm{y}}, \mathrm{SiO}_{2}$, distilled water, $\mathrm{NH}_{4} \mathrm{OH}, \mathrm{CH}_{4}$, $\mathrm{CO}_{2}$, and $\mathrm{N}_{2}$.

\subsection{Block Diagram}

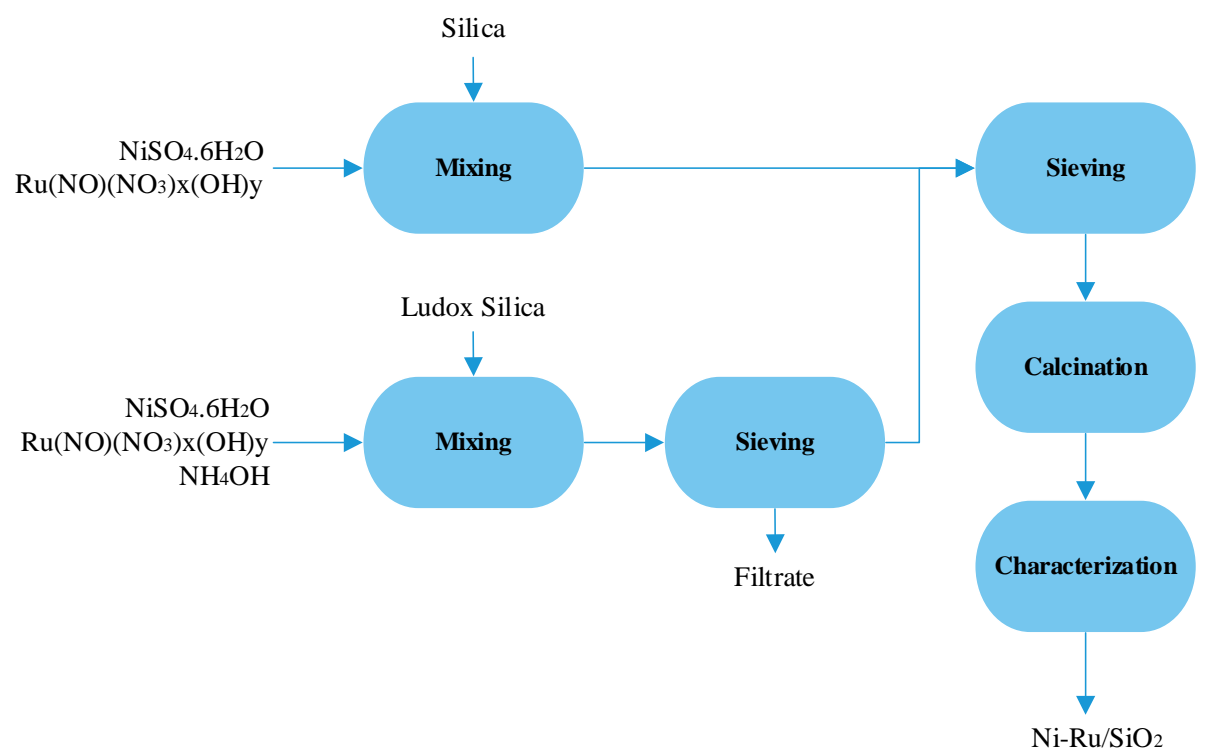

Figure 2. Block Diagram of Catalyst Synthesis

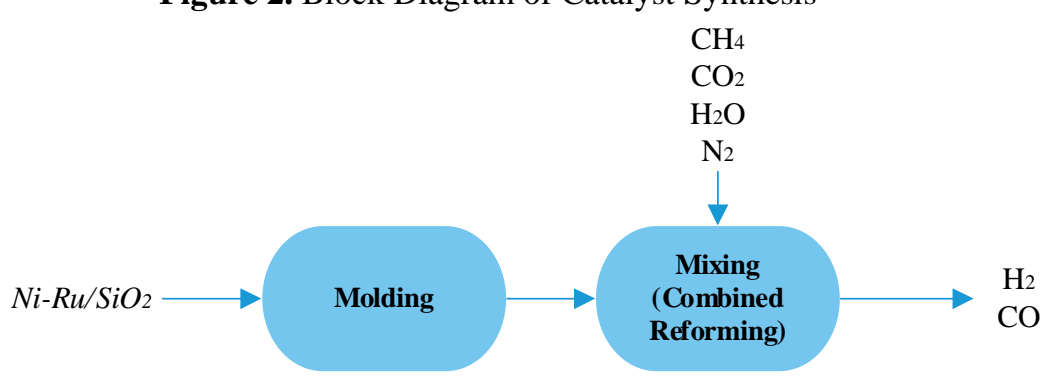

Figure 3. Block Diagram of Dry Reforming Process

\subsection{Catalyst Synthesis}

The catalyst preparation was conducted using two different synthesis protocols: via the sol gel-coprecipitation (NRS-SgCo) method and the impregnation (NRS-Im) method. The NRS-SgCo sample was prepared by dissolving $6.03 \mathrm{~g}$ and $7.42 \mathrm{~g}$ of $\mathrm{NiSO}_{4} .6 \mathrm{H}_{2} \mathrm{O}$ for the NRS-SgCo 1 and NRS-SgCo 2 samples respectively, in $100 \mathrm{~mL}$ of 
distilled water. As much as $1.5 \mathrm{~g}$ and $0.11 \mathrm{~g}$ of $\mathrm{Ru}(\mathrm{NO})\left(\mathrm{NO}_{3}\right)_{\mathrm{x}}(\mathrm{OH})_{\mathrm{y}}$ were added to the corresponding nickel precursor solution, followed by the addition of $30.14 \mathrm{~g} \mathrm{SiO}_{2}$ (Ludox). Afterward, the solution was mixed at a temperature of $70^{\circ} \mathrm{C}$ and a rotation speed of $180 \mathrm{rpm}$ [6]. During the mixing process of sample NRS-SgCo, $\mathrm{NH}_{4} \mathrm{OH}$ was gradually added into the solution until a pH of 9 was attained. The mixing process was carried out overnight and followed by filtration [7]. The preparation of the NRS-Im sample was initiated with the preparation of catalyst solution similar to the protocols used in the preparation of NRS-SgCo. However, the $\mathrm{SiO}_{2}$ was used in the impregnation method. The solution was mixed at a temperature of $70^{\circ} \mathrm{C}$ and a rotation speed of $300 \mathrm{rpm}$ until it transformed into a slurry.

The filtered NRS-SgCo sample and the NRS-Im sample that has become a slurry were dried in the oven at $110^{\circ} \mathrm{C}$ overnight [8]. Afterward, the NRS-SgCo and NRS-Im samples were ground using a mortar and pestle, followed by sieving with the 80-mesh sieve. The sieved NRS-SgCo and NRS-Im were then calcined in the furnace at $400^{\circ} \mathrm{C}$ with a temperature rise rate of $2^{\circ} \mathrm{C}$ per minute for $6 \mathrm{~h}$.

\subsection{Catalyst Characterization}

The size and phase of the catalyst particles were characterized using an X-ray diffractometer (XRD) with Cu Ka radiation and the angle between transmitted beam and reflected beam (2 Theta) range is $3-90^{\circ}$. The surface area and porosity of the catalysts were measured using a Brunauer Emmett Teller (BET) surface analyzer via nitrogen adsorption at $77 \mathrm{~K}$ using the Nova Station A Quantachrom version 11.04 Instrument. The XRD patterns were analyzed using Xpert software to determine the peaks, full width at half maximum (FWHM), and phase of the catalyst material. The XRD patterns were normalized and plotted on OriginLab. The crystallite sizes were estimated using the Scherrer equation. The catalyst was then subject to catalytic performance investigation for the decomposition of $\mathrm{CH}_{4}$ into syngas.

\subsection{Decomposition of $\mathrm{CH}_{4}$ into Syngas}

The dry reforming technique was used to study the decomposition process of $\mathrm{CH}_{4}$ into syngas. Initially, 15 catalyst pellets were prepared from $0.1 \mathrm{~g}$ of catalyst. The pellets were fabricated under a pressure of $20 \mathrm{bar}$. The pelletized catalyst was subsequently inserted into the reactor. The study was carried out with a $\mathrm{CO}_{2}: \mathrm{CH}_{4}: \mathrm{N}_{2}$ volumetric flow rate ratio of $0: 100: 100: 50$. The production of syngas was conducted in a fixed bed reactor operated at atmospheric pressure and a temperature of $850^{\circ} \mathrm{C}$. Afterwards, the syngas produced was analyzed using a gas chromatography using Parkin - Elmer gas chromaography instrument to determine the composition of the gas mixture.

\section{RESULTS AND DISCUSSION}

Syngas was produced using $\mathrm{Ni}-\mathrm{Ru} / \mathrm{SiO}_{2}$ catalyst with an optimum $\mathrm{CO}_{2}, \mathrm{CH}_{4}$, and $\mathrm{N}_{2}$ ratio as the reactants. The synthesis of the catalysts was carried out using different synthesis methods. The catalysts were characterized using XRD and BET. The catalytic performance of the catalyst to produce syngas was also investigated.

\subsection{Catalyst Characterization Results}

Prior to the catalytic performance investigation, the catalysts were characterized for their surface areas, pore diameters, pore volumes, phase compositions, and crystallite sizes. The characterization results are summarized in Table 1.

\subsubsection{BET Analysis Results}

The surface area, pore diameter, and pore volume of the catalysts were measured using a BET surface area analyzer. Using the surface areas of silica and final catalysts (Table 1), the decrease in the surface area of silica can be calculated. In the sample obtained from the sol gel-coprecipitation method, a surface area reduction of $54.7 \%$ and $51.13 \%$ was observed in samples 1 and 2, respectively. Meanwhile, the sample prepared using the impregnation method underwent a surface area decrease of $41.64 \%$ and $38.68 \%$ for samples 1 and 2, respectively. The surface area reduction is expected due to the presence of metal that covers the pores of the catalyst [9].

In this study, it was observed that the addition of nickel resulted in an increase in the surface area of the catalyst. This is in good agreement with a study conducted by Wang et al. (2018) that shows that the number of Ni active sites correspond to the ability of the Ni species to be reduced. The amount of $\mathrm{Ni}$ also affects the size and surface area of Ni particles [10]. 
From the pore diameter measurements presented in Table 1, it can be inferred that the catalyst prepared using both coprecipitation and impregnation methods exhibited comparable pore diameters.

Table 1. Characteristics of $\mathrm{Ni}-\mathrm{Ru} / \mathrm{SiO}_{2}$ Catalysts

\begin{tabular}{|c|c|c|c|c|c|c|}
\hline Catalyst & Method & $\begin{array}{c}\text { Surface } \\
\text { Area }\left(\mathrm{m}^{2} / \mathrm{g}\right) \\
\end{array}$ & $\begin{array}{c}\text { Pore Diameter } \\
\text { (nm) }\end{array}$ & $\begin{array}{c}\text { Pore Volume } \\
\text { (cc/g) }\end{array}$ & Phase & $\begin{array}{l}\text { Crystallite } \\
\text { Size (nm) }\end{array}$ \\
\hline *Ludox Silica & $\begin{array}{c}\text { Sol gel - } \\
\text { Coprecipitation }\end{array}$ & 135 & 22 & - & - & - \\
\hline **Solid Silica & Impregnation & 250 & 20 & - & - & - \\
\hline NRS-SgCo 1 & $\begin{array}{c}\text { Sol gel - } \\
\text { Coprecipitation }\end{array}$ & 61.13 & 0.883 & 0.043 & $\begin{array}{c}\mathrm{NiO} \\
\mathrm{RuO}_{2} \\
\mathrm{SiO}_{2}\end{array}$ & $\begin{array}{r}90.6567 \\
86.6738 \\
103.3987\end{array}$ \\
\hline NRS-SgCo 2 & $\begin{array}{c}\text { Sol gel - } \\
\text { Coprecipitation }\end{array}$ & 65.98 & 0.883 & 0.047 & $\begin{array}{c}\mathrm{NiO} \\
\mathrm{RuO}_{2} \\
\mathrm{SiO}_{2}\end{array}$ & $\begin{array}{l}70.9792 \\
76.9572 \\
77.5182\end{array}$ \\
\hline NRS-Im 1 & Impregnation & 145.9 & 0.844 & 0.101 & $\begin{array}{c}\mathrm{NiO} \\
\mathrm{RuO}_{2} \\
\mathrm{SiO}_{2}\end{array}$ & $\begin{array}{r}114.41 \\
41.4126 \\
49.3669\end{array}$ \\
\hline NRS-Im 2 & Impregnation & 153.3 & 0.844 & 0.107 & $\begin{array}{c}\mathrm{NiO} \\
\mathrm{RuO}_{2} \\
\mathrm{SiO}_{2}\end{array}$ & $\begin{array}{r}71.5638 \\
136.2165 \\
17.1325\end{array}$ \\
\hline
\end{tabular}

Remarks: * : : $\quad$ :www.sigmaaldrich.com

** : www.hwnanomaterial.com

\subsubsection{XRD Analysis Results}

A deep analysis of the XRD patterns using Xpert software was conducted to determine the type and crystalline phase composition of the $\mathrm{Ni}-\mathrm{Ru} / \mathrm{SiO}_{2}$ samples. Based on the results depicted in Figures 4a,b,c, it can be seen that all samples contain silica in its amorphous form, which corresponds to the peak broadening at the $2 \theta$ of 20 to $21^{\circ}$ (JCPDS No. 052-1279).

The XRD patterns of the catalysts prepared using the sol gel-coprecipitation method with different amounts of nickel showed an identical crystal structure, rhombohedral (Figure 4c). The rhombohedral NiO structure is indicated by the four peaks with the highest intensity at the $2 \theta$ of $18.6^{\circ} ; 48.67^{\circ} ; 64.28^{\circ}$; and $80.42^{\circ}$ according to the JCPDS No. 085-1977. Meanwhile, the catalysts obtained from the impregnation process with different amounts of nickel resulted in different $\mathrm{NiO}$ crystal structures: the cubic structure at the $2 \theta$ of $62.8^{\circ} ; 75.45^{\circ}$; and $79.98^{\circ}$ based on the JCPDS No. 002-1216 (Figure 4a) and monoclinic structure at the $2 \theta$ of $79.13^{\circ}$ according to the JCPDS No. 072-1464 (Figure 4b).

In the samples synthesized using the sol gel-coprecipitation, the $\mathrm{RuO}_{2}$ phase shows three peaks with the highest intensity at the $2 \theta$ of $28.32^{\circ} ; 35.06^{\circ}$; and $58.41^{\circ}$, ᄀwhich corresponds to the orthorhombic structure according to the JCPDS No. 088-0323 (Figure 4c). The sample prepared using the impregnation method indicates $\mathrm{RuO}_{2} \mathrm{Phase}$ with different crystal structures: tetragonal at the $2 \theta$ of $34.92^{\circ} ; 35.31^{\circ} ; 58.25^{\circ}$ and $86.64^{\circ}$ based on the JCPDS No. 088-0322 (Figure 4a) and cubic structure at the $2 \theta$ of $32.2^{\circ}$ and $67.1^{\circ}$ based on the JCPDS No. 050-1428 (Figure 4b).

The presence of $\mathrm{NiO}, \mathrm{RuO}_{2}$, and $\mathrm{SiO}_{2}$ phases in all samples is in good agreement with some studies conducted by Wysocka et al. (2019), Liu et al. (2018), and Yuan et al. (2015). This implies that the catalysts were successfully synthesized. 


\section{a}

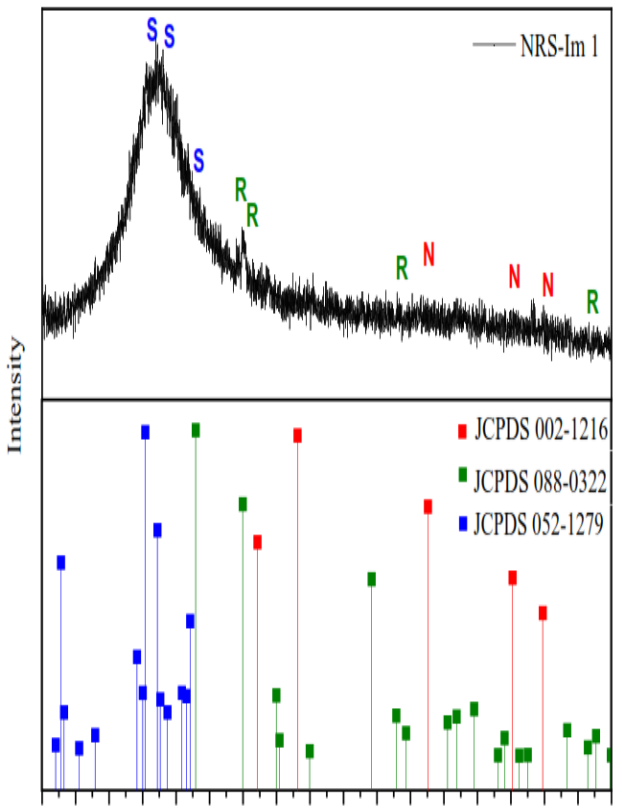

$\begin{array}{llllllllllllllllll}5 & 10 & 15 & 20 & 25 & 30 & 35 & 40 & 45 & 50 & 55 & 60 & 65 & 70 & 75 & 80 & 85 & 90\end{array}$

2 Theta b

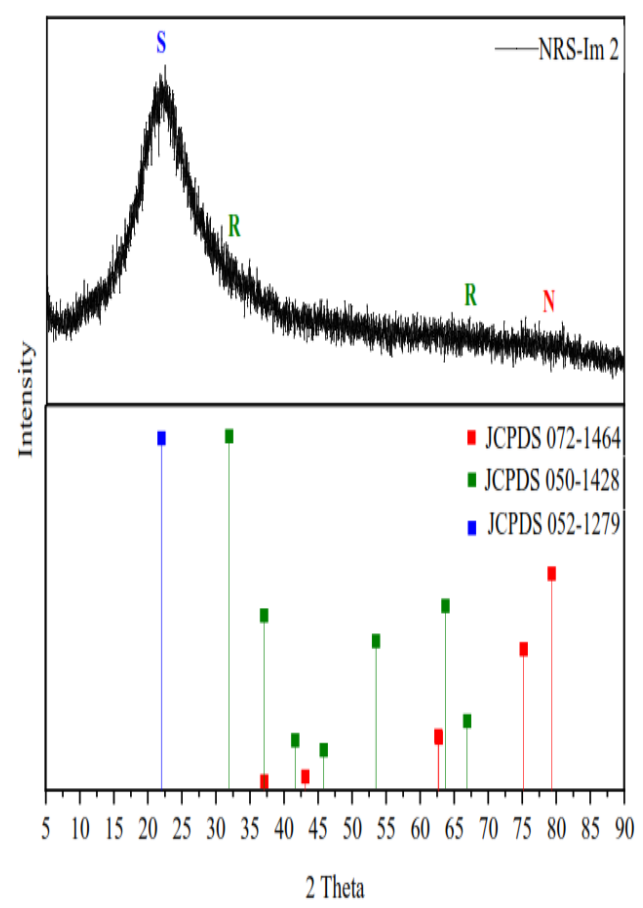

C

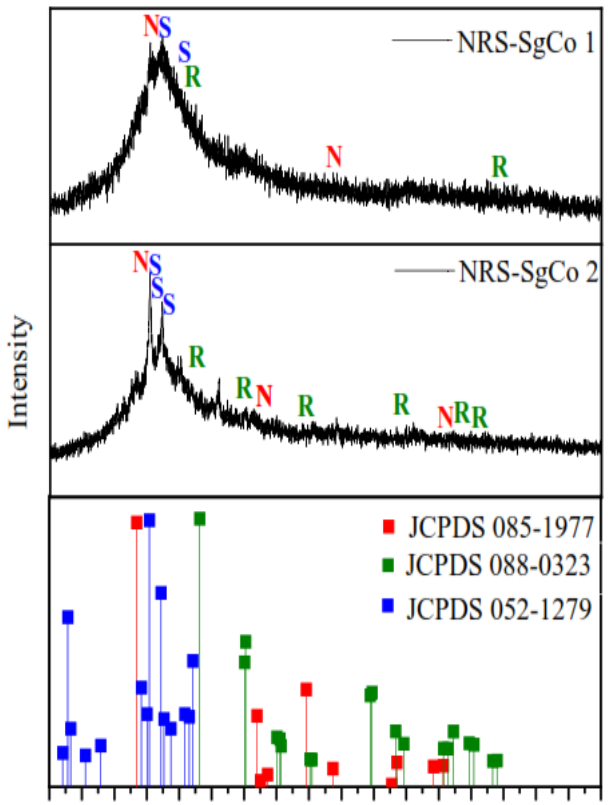

51015202530354045505560657075808590

2 Theta

Figure 4. XRD patterns of (a) NRS-Im 1 sample, (b) NRS-Im 2 sample, and (c) NRS-SgCo 1 and NRS- SgCo 2 samples

\subsection{Catalytic Activity Test Results}

In this study, the dry reforming reaction was used in the production of syngas. The primary reaction of the dry reforming is stated in Equation (1).

$\mathrm{CO}_{2}+\mathrm{CH}_{4} \rightarrow 2 \mathrm{CO}+2 \mathrm{H}_{2}$

After catalyst characterization, the catalytic activity of the catalyst was investigated for the dry reforming reaction. The results of the catalytic activity tests are presented in Figure 5. 

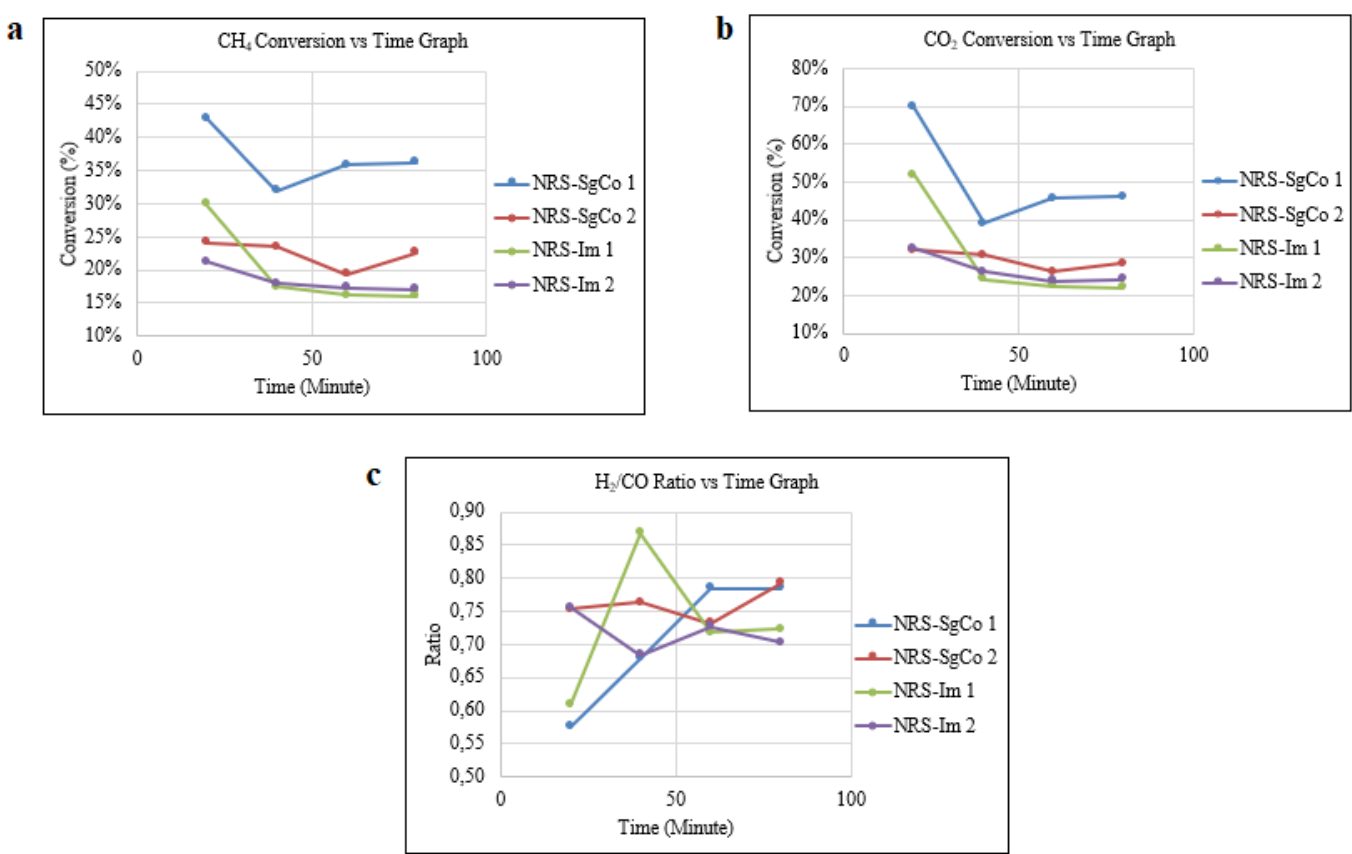

Figure 5. Results of the catalytic activity test: (a) Conversion of $\mathrm{CH}_{4}$ vs. time, (b) Conversion of $\mathrm{CO}_{2}$ vs. time, (c) $\mathrm{H}_{2} / \mathrm{CO}$ Ratio vs. time

Based on Figure 6, the dry reforming process involving the catalyst prepared using the impregnation method shows lower $\mathrm{CH}_{4}$ and $\mathrm{CO}_{2}$ conversions than the reaction process with the catalyst prepared using the sol gelcoprecipitation method. This is likely due to the lower thermal stability of the catalyst prepared using the impregnation method. From the literature, the catalyst with lower thermal stability tends to induce a considerable surface area reduction [14]. The high surface area is important to enhance heat and mass transfers, resulting in the increased conversion efficiency of the reactants, $\mathrm{CH}_{4}$ and $\mathrm{CO}_{2}$, into products [15].

In this study, the ratio of $\mathrm{H}_{2} / \mathrm{CO}$ obtained from the catalyst prepared using either impregnation or sol gelcoprecipitation techniques did not show any significant differences because of the identical pore diameters. Referring to the previous studies, the ratio of $\mathrm{H}_{2} / \mathrm{CO}$ is influenced by the pore diameter of the catalyst [16]. The $\mathrm{H}_{2} / \mathrm{CO}$ ratio in this study is in the range of $0.7-0.8$. This ratio is the optimum ratio of syngas that can be utilized as an intermediate product for the production of gasoline or diesel [1].

The catalytic activity of the catalyst was compared with the activity of the materials prepared by Han et al. (2020), Miao et al. (2020), and Li et al. (2018). This was performed to understand the effectivity of the $\mathrm{Ni}-\mathrm{Ru} / \mathrm{SiO}_{2}$ catalyst compared to other materials from the literature. The comparison of the catalytic activity with other materials is shown in Figure 6.

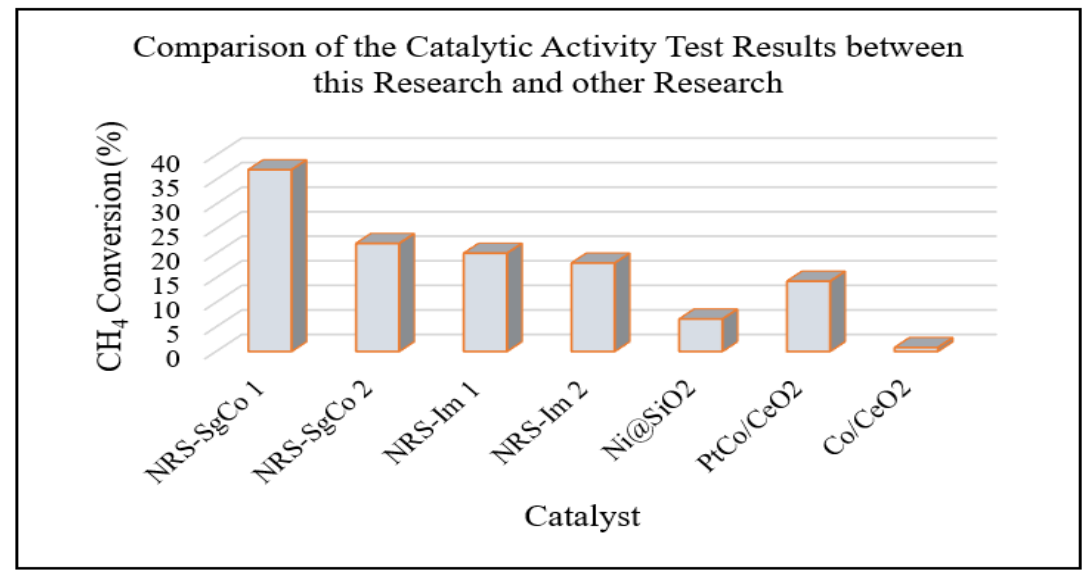

Figure 6. Comparison of the catalytic activity of the $\mathrm{Ni}-\mathrm{Ru} / \mathrm{SiO}_{2}$ catalyst with other materials from the literature 
According to Figure 6, the highest $\mathrm{CH} 4$ conversion was obtained using the catalyst prepared in this study (sample NRS-SgCo 1, NRS-SgCo 2, NRS-Im 1, and NRS-Im 2). As the CH4 conversion increases, the syngas production also increases. Compared to another study with a similar catalyst conducted by Wysocka et al. (2019), the $\mathrm{H} 2 / \mathrm{CO}$ ratio obtained from this study is $114 \%$ higher. This implies that the selectivity of our $\mathrm{Ni}-\mathrm{Ru} / \mathrm{SiO} 2$ catalyst is significantly higher.

\section{CONCLUSION}

In summary, $\mathrm{Ni}-\mathrm{Ru} / \mathrm{SiO}_{2}$ catalysts were successfully prepared using different synthesis protocols. The XRD analysis showed that the catalysts prepared using either sol gel-coprecipitation or impregnation methods indicated $\mathrm{NiO}, \mathrm{RuO}_{2}$, and $\mathrm{SiO}_{2}$ phases. The results suggest that the sol-gel coprecipitation is a suitable method to optimize the performance of the catalyst due to higher thermal stability than the catalyst prepared using the impregnation method, which can be noticed from the higher $\mathrm{CH}_{4}$ and $\mathrm{CO}_{2}$ conversion. The $\mathrm{Ni}-\mathrm{Ru} / \mathrm{SiO}_{2}$ catalysts prepared in this study also possess higher catalytic activity compared to other catalysts from the literature. Moreover, the Ni$\mathrm{Ru} / \mathrm{SiO}_{2}$ catalyst also produced $114 \%$ higher amounts of syngas than another study from the literature with similar catalyst materials.

\section{ACKNOWLEDGEMENTS}

The authors acknowledge the financial support from the Ministry of Research, Technology and Higher Education of Indonesia through the Student Creativity Program in Research for the financial year 2021. All authors would like to thank the Student Affairs and Alumni Division of Universitas Sebelas Maret.

\section{REFERENCES}

[1]. R.B. Jackson, M. Saunois, J.G. Canadell, B. Poulter, A.R. Stavert, P. Bergamaschi, P. Bousquet, Y. Niwa, A. Segers, A. Tsuruta, "Increasing Anthropogenic Methane Emissions Arise Equally from Agricultural and Fossil Fuel Sources,” Environ. Res. Lett. 15 1-8 (2020). https://doi.org/10.1088/1748-9326/ab9ed2.

[2]. L. Hockstad, and L. Hanel. (2018). Inventory of U.S. Greenhouse Gas Emissions and Sinks. United States. Available: https://www.osti.gov/dataexplorer/biblio/dataset/1464240 [Accessed: 2 February 2021]

[3]. H.J. Chae, J.H. Kim, S.C. Lee, H.S. Kim, S. Bin Jo, J.H. Ryu, T.Y. Kim, C.H. Lee, S.J. Kim, S.H. Kang, J.C. Kim, M.J. Park, "Catalytic Technologies for CO Hydrogenation for the Production of Light Hydrocarbons and Middle Distillates,” Catalysts. 10 1-32 (2020). https://doi.org/10.3390/catal10010099.

[4]. P. Lu, Q. Huang, A.C. Bourtsalas, Y. Chi, J. Yan, "Effect of Operating Conditions on the Coke Formation and Nickel Catalyst Performance During Cracking of Tar," Waste and Biomass Valorization. 10 155-165 (2019). https://doi.org/10.1007/s12649-017-0044-5.

[5]. R. Singh, A. Dhir, S.K. Mohapatra, S.K. Mahla, "Dry Reforming of Methane using Various Catalysts in The Process : review," Biomass Conversion and Biorefinery.10 1-21 (2019).

[6]. A.W. Budiman, S.H. Song, T.S. Chang, M.J. Choi, "Preparation of a High Performance Cobalt Catalyst for CO2 Reforming of Methane,” Adv. Powder Technol. $27 \quad 584-590$ (2016). https://doi.org/10.1016/j.apt.2016.01.029.

[7]. A.W. Budiman, S.H. Song, T.S. Chang, M.J. Choi, "Preparation of a High Performance Cobalt Catalyst for CO2 Reforming of Methane,” Adv. Powder Technol. $27 \quad 584-590$ (2016). https://doi.org/10.1016/j.apt.2016.01.029.

[8]. I. Wysocka, J. Hupka, A. Rogala, "Catalytic Activity of Nickel and Ruthenium - Nickel Catalysts Supported on $\mathrm{SiO} 2, \mathrm{ZrO} 2, \mathrm{Al2O}$, and MgAl2O4 in A Dry Reforming Process," Catalysts. 9 1-13 (2019).

[9]. D. Yao, H. Yang, H. Chen, P.T. Williams, "Co-precipitation, Impregnation and Sol Gel Preparation of Ni Catalysts for Pyrolysis-Catalytic Steam Reforming of Waste Plastics,” Appl. Catal. B Environ. 239 565-577 (2018). https://doi.org/10.1016/j.apcatb.2018.07.075.

[10]. Y. Prasetyaningsih, Hendriyana, H. Susanto, "Influence of impregnation and coprecipitation method in preparation of $\mathrm{Cu} / \mathrm{ZnO}$ catalyst for methanol synthesis," J. Eng. Technol. Sci. 48 442-450 (2016). https://doi.org/10.5614/j.eng.technol.sci.2016.48.4.6.

[11]. S. Wang, Z. Tian, Q. Liu, Y. Qiao, Y. Tian, "Facile preparation of a Ni/MgAl2O4 catalyst with high surface area: Enhancement in activity and stability for CO methanation," Main Gr. Met. Chem. 41 73-89 (2018). https://doi.org/10.1515/mgmc-2018-0003.

[12]. S.S. Itkulova, G.D. Zakumbaeva, A.A. Mukazhanova, Y.Y. Nurmakanov, "Syngas production by biogas 
reforming over the co-based multicomponent catalysts," Cent. Eur. J. Chem. 12 1255-1261 (2014). https://doi.org/10.2478/s11532-014-0571-x.

[13]. Y. Liu, W. Sheng, Z. Hou, Y. Zhang, "Homogeneous and highly dispersed ni-ru on a silica support as an effective co methanation catalyst," RSC Adv. 8 2123-2131 (2018). https://doi.org/10.1039/c7ra13147j.

[14]. C. Yuan, N. Yao, X. Wang, J. Wang, D. Lv, X. Li, "The SiO2 supported bimetallic Ni-Ru particles: A good sulfur-tolerant catalyst for methanation reaction,” Chem. Eng. J. 260 1-10 (2015). https://doi.org/10.1016/j.cej.2014.08.079.

[15]. G. Xiang, V. Alejandro, B. Alicia, B. Roman, H. Jim, L. Wojciech, T. Antonio, "Efficient Ceria Nanostructures for Enhanced Solar Fuel Production via High Temperature Thermochemical Redox Cycles," J. Mater. Chem. A. 4 9614-9624 (2016).

[16]. M. Heya, X. Gao, A. Tricoli, W. Lipiński, "Effect of specific surface area on syngas production performance of pure ceria in high-temperature thermochemical redox cycling coupled to methane partial oxidation," RSC Adv. 10 36617-36626 (2020). https://doi.org/10.1039/d0ra06280d.

[17]. J.V. Luke, P. Nicholas, R. Stephen, S. Andreas, H.D. Jane, "The Effect of Morphology on the Oxidation of Ceria by Water and Carbon Dioxied,” J. Sol. Energy Eng. 134 148-162 (2012).

[18]. S. Sadaka, “Gasification, Producer Gas and Syngas,” Agric. Nat. Resour. 158 (2017).

[19]. B. Han, L. Zhao, F. Wang, L. Xu, H. Yu, Y. Cui, J. Zhang, W. Shi, "Effect of Calcination Temperature on the Performance of the Ni@SiO2Catalyst in Methane Dry Reforming,” Ind. Eng. Chem. Res. 59 1337013379 (2020). https://doi.org/10.1021/acs.iecr.0c01213.

[20]. C. Miao, G. Zhou, S. Chen, H. Xie, X. Zhang, "Synergistic effects between $\mathrm{Cu}$ and $\mathrm{Ni}$ species in $\mathrm{NiCu} / \gamma$ Al2O3 catalysts for hydrodeoxygenation of methyl laurate," Renew. Energy. 153 1439-1454 (2020). https://doi.org/10.1016/j.renene.2020.02.099.

[21]. Z. Li, S. Das, P. Hongmanorom, N. Dewangan, M.H. Wai, S. Kawi, "Silica-based micro- and mesoporous catalysts for dry reforming of methane,” Catal. Sci. Technol. 8 2763-2778 (2018). https://doi.org/10.1039/c8cy00622a. 